Research Article

\title{
Collapse Potential of Loess under Unloading Effect
}

\author{
Xin Jin $\mathbb{D}^{1},{ }^{1}$ Tie-Hang Wang, ${ }^{2}$ Zai-Kun Zhao, ${ }^{2}$ Liang Zhang $\mathbb{D}^{2},{ }^{2}$ and Yan-Zhou Hao $\mathbb{D}^{3}$ \\ ${ }^{1}$ College of Civil and Architecture Engineering, Xi'an Technological University, Xi'an 710021, China \\ ${ }^{2}$ College of Civil Engineering, Xi'an University of Architecture and Technology, Xi'an 710055, China \\ ${ }^{3}$ School of Civil and Transportation Engineering, Henan University of Urban Construction, Pingdingshan 467300, China \\ Correspondence should be addressed to Xin Jin; jinx_geomech@163.com
}

Received 30 November 2020; Revised 20 December 2020; Accepted 16 January 2021; Published 29 January 2021

Academic Editor: Song-He Wang

Copyright (c) 2021 Xin Jin et al. This is an open access article distributed under the Creative Commons Attribution License, which permits unrestricted use, distribution, and reproduction in any medium, provided the original work is properly cited.

\begin{abstract}
Collapsible loess is generally characterized by a sudden and substantial decrease in volume that occurs when is applied under constant stress. To evaluate the loess collapse potential, the self-weight collapse and collapse coefficients have been defined by the code for building construction in collapsible loess regions. However, the method in the code does not account for the vertical stress variation. The loess collapse process commonly occurs with stress variation in practice. This paper documents a low-cost, quantitative evaluation scheme using regression analysis to evaluate the loess collapse potential by varying the unloading levels. The results show that the factors that prominently account for loess collapse deformation are the initial pressure, unloading ratio, and collapse completed-ratio. At a constant collapse-completed ratio, the remnant collapse coefficient significantly decreases with the decreasing unloading ratio; at a constant unloading ratio, the remnant collapse coefficient increases with a decreasing collapse-completed ratio. Decreasing unloading and collapsecompleted ratios decreased the loess collapse potential with an initial pressure that exceeds the threshold value. Finally, an unloading collapse deformation calculation of loess was prepared to analyze practical project problems of loess based on the unloading collapse test.
\end{abstract}

\section{Introduction}

Loess is an aeolian deposit of yellowish dust mostly formed during the Quaternary period [1-3]. Loess deposits cover $640000 \mathrm{~km}^{2}$, distributed mainly along the middle reaches of the Yellow River Valley, constituting one of the most important parts of the Chinese regional and physical geography and the Loess Plateau. Because of its collapse behavior and other associated geotechnical engineering issues, such as landslides, hydro-consolidation, and wetting-induced collapse, loess belongs to problematic soils and has been the subject of geotechnical research and practice since the 1960s [4-14]. Following the adoption of "the belt and road" strategy, infrastructure construction in the Loess Plateau will develop more vigorously. Therefore, before the design and construction on the loess field, it is important to determine the loess collapse value. The evaluation method for the loess collapse at present mainly concentrates on the constant loading and humidification or dehumidification.

At present, there are two ways to study the collapse of loess under constant load: one is the combination of the laboratory test and numerical calculation method; the other is the field immersion test. Rogers et al. [15] through the monitoring results of shear wave velocity and resistivity in the process of loess collapse reflected the collapse deformation characteristics of intact loess under constant pressure. Francisca [9] analyzed data from in situ and laboratory test to establish possible correlations between the high strain elastic properties of loess and results from SPT. Jiang et al. $[16,17]$ summarized experimental studies on wetting-induced collapsibility in loess using single oedometer, double oedometer, and triaxial wetting tests and presented a distinct element method (DEM) to investigate its macromechanical and micromechanical behavior (compression and collapse behavior) under one-dimensional compression condition. Wang et al. [18] conducted a 40-meter-diameter soaking test in the field with self-weight collapsible loess at a thickness of $36.5 \mathrm{~m}$ in order to study the deformation property of largethickness self-weight collapsible loess. Deng et al. [19] conducted a collapse assessment by combining the laboratory and in situ soaking tests. The reasons for the significant difference in collapse settlement between the in situ soaking 
tests and the calculated estimates were discussed. Li et al. [20] investigated the functional mechanism of loess collapse for a tunnel structure by conducting a large-field water immersion test on the ground surface above an existing loess tunnel. The subsidence of the loess during the long-term water immersion test was measured and analyzed to reveal the collapsible deformation characteristics of the loess tunnel site. Wang et al. [2] proposed a method for analyzing and evaluating the collapsibility of loess by combining the relationship between the compression and initial structural properties of loess.

Because the strength of grain connection of loess is not fixed, it changes with the variety of water content. After the first humidification, the connecting grains between loess grains are weakened properly, and the loess will be rebalanced under the new strength condition after a small amount of collapse occurs. Then, the loess was humidified again, and a little collapse occurred. After many times of wetting, the collapse reaches the maximum value after saturation [21]. In the practical project, the collapse often occurs in the case of different depth loess layers reaching different moisture content, so it is of significance to study the collapse deformation law of loess under the effect of increasing and decreasing moisture. Shao et al. [22-24] based on the triaxial test of Q3 loess, the initial tangent modulus of loess with different water content under the given confining pressure under axial loading is measured, and the damage evolution characteristics of the loess structure during humidification are investigated according to the variety of modulus. Liu et al. [25] proposed the secant modulus algorithm of loess wetting deformation based on a large number of single and double line loess methods, and the collapse deformation or humidification deformation of loess foundation is obtained. Zhang et al. [26] obtained the wetting deformation of loess according to the difference of the $e-p$ curve of the unimmersed loess sample under different initial water content. $\mathrm{Xu}$ et al. [27] simulated field conditions involving flood irrigation on a cracked loess plateau surface and studied their effects on the loess deformation. $\mathrm{Ng}$ et al. [28] conducted a laboratory test to investigate the effects of the microstructure on the water retention curve and wetting and drying-induced volume change in loess. An et al. [29] studied the settling characteristics of loess through a field immersion test on thick collapsible loess. Weng et al. [30] investigated the mechanisms that influence wetting-induced collapse deformation of loess strata on the lining structure of a subway tunnel. Hou et al. [31] highlighted the dependence of loess collapse deformation on the infiltration processes and estimated the in situ collapse characteristics.

At present, the research on loess collapse mainly focuses on the effect of constant load and humidification, which solves a lot of practical engineering problems; however, there is still a lack of research literature and analysis and evaluation methods for loess unloading collapse, which makes the design of loess unloading collapsible engineering lack of scientific basis. The current loess collapse evaluation method does not account for the vertical stress variation. For example, the engineering experience shows that the additional settlement of loess between the piles occurs because of the inundation with construction on bored pile foundations in the self-weight collapsible loess area. Then, the negative friction of the piles [32-34], which develop during the collapse of loess, reacts on the loess and reduces the vertical stress of loess around the piles. The loess collapse often occurs with the unloading process caused by the pile negative friction. Unfortunately, the engineering design and problem analysis are limited by the lack of collapse deformation characteristics' research of loess between piles.

This paper focused on the unloading effect during the loess collapse process and provided an innovative evaluation method for the loess collapse potential of unloading. The loess unloading collapse behavior was analyzed. The loess collapse influence coefficient of unloading was investigated. The research work is significant to supplement and improve the evaluation method of loess collapse and to promote a scientific design method of bored concrete-pile composite foundation in the self-weight collapsible loess site by considering the loess unloading effect.

\section{Influence Factors of Unloading Collapse}

According to the engineering conditions of unloading collapse of the loess site, two factors were considered in the process of loess collapse under the effect of unloading: the completion degree of loess collapse when unloading occurred and the magnitude of the unloading amount during unloading. Therefore, in order to define the process of unloading collapse, the following parameters were defined.

The collapse-completed degree of loess was represented by the collapse-completed ratio $\eta$, which is calculated using

$$
\eta=\frac{S_{1}}{S} \times 100 \%
$$

where $S_{1}$ is the completed collapse amount $(\mathrm{mm})$ of loess under the initial pressure and $S$ is the total collapse amount $(\mathrm{mm})$ of loess under the initial pressure. The initial pressure is unloaded at different degrees when $\eta$ reaches $20 \%, 40 \%$, $60 \%$, and $80 \%$.

To evaluate the unloading amplitude, the unloading ratio $K$ is calculated using

$$
K=\frac{p_{1}-\Delta p}{p_{1}}=\frac{p_{r}}{p_{1}},
$$

where $p_{1}$ is the initial pressure $(\mathrm{kPa}), p_{\mathrm{r}}$ is the remnant pressure after unloading $(\mathrm{kPa})$, and $\Delta p$ is the vertical pressure released when unloading occurs during loess collapse $(\mathrm{kPa})$.

Due to the decrease of vertical pressure during unloading, the collapse deformation of loess should be less than that under constant initial pressure $p_{1}$. In order to express the value of uncompleted collapse of intact loess under the effect of unloading, the ratio of uncompleted collapse $S_{\mathrm{r}}$ to initial height $h_{0}$ is defined as the coefficient of collapse reduced by unloading. The remnant collapse 
characteristic is represented by the remnant collapse coefficient $\delta_{\mathrm{r}}$, which is calculated using

$$
\delta_{r}=\frac{S-S_{1}-S_{2}}{h_{0}}=\frac{S_{r}}{h_{0}},
$$

where $S$ is the total collapse deformation of the loess under pressure $p_{1}(\mathrm{~mm}), S_{1}$ is the collapse of loess under pressure $p_{1}$ before unloading $(\mathrm{mm}), S_{2}$ is the collapse of loess under pressure $p_{\mathrm{r}}$ after unloading $(\mathrm{mm}), S_{\mathrm{r}}$ is the uncompleted collapse of intact loess after unloading $(\mathrm{mm})$, and $h_{0}$ is the initial loess sample height $(\mathrm{mm})$.

\section{Experimental Investigation}

3.1. Intact Loess in the Test. The tested intact loess was collected from a site in the Tongchuan area, north-western Chinese Loess Plateau. The site investigation and the basic physical properties of soil samples have been carried out in the selection of soil sampling sites. When sampling on-site, it is necessary to ensure the integrity of soil samples without cracks. In order to avoid disturbance to the undisturbed soil sample, the sampling process is all made by manual cutting with soil cutter. After sampling, the soil sample is cut into a soil column with a height of about $30 \mathrm{~cm}$ and a diameter of $12 \mathrm{~cm}$. During sampling, the moisture content and density of soil samples shall be measured and recorded. We have avoided tree root, gravel, and other parts and selected the location with relatively uniform soil sample properties for sampling. Since the sampling site is a building foundation pit, the manual cutting method is adopted (the depth of soil sampling is $5.0 \sim 8.5 \mathrm{~m}$ ). These specimens are yellow-brown in color, porous, and contain a small amount of calcareous nodules. The sampling process is shown in Figure 1.

According to the "standard for the soil test method" (GB/T 50123-1999) [35], the physical properties of undisturbed loess are tested. The particle size gradation was measured by the Bettersize 2000 laser particle size analyzer (Figure 2).

Three groups of parallel tests were carried out for each group of samples. If the results meet the reasonable scope stipulated in the standard, the average value is taken as the final index. The basic physical properties of intact loess are shown in Table 1.

3.2. Collapse Coefficient $\delta$ s of Loess under Different Initial Pressure $p_{1}$. According to the "standard for building construction in collapsible loess regions” (GB 50025-2018) [36], the collapse coefficient $\delta_{\mathrm{s}}$ of loess is given as follows:

$$
\delta_{s}=\frac{S}{h_{0}},
$$

where $S$ is the total collapse deformation of the loess under pressure $p_{1}(\mathrm{~mm})$ and $h_{0}$ is the initial loess sample height $(\mathrm{mm})$.

The collapse coefficient $\delta_{s}$ and initial collapse pressure $p_{\text {sh }}$ of loess measured by the laboratory test should meet the following requirements:

(1) The quality grade of the soil sample is grade I, which is intact soil sample.
(2) The size of the ring knife: $\varphi=79.8 \mathrm{~mm}$ and $h=20 \mathrm{~mm}$. Before use, the ring knife is cleaned and air dried, and the permeable stone is dried and cooled.

(3) Before loading, the loess sample should be kept in natural water content.

(4) The stability standard of the sample before or after immersion should be that the settlement per hour is not more than $0.01 \mathrm{~mm}$.

When determining the collapse coefficient of intact loess, the double-line compression test was adopted. When $p_{1}$ is in the range of $0-200 \mathrm{kPa}$, the collapse coefficients of intact loess under different $p_{1}$ actions are measured, as shown in Figure 3 and Table 2.

It can be seen from Figure 3 and Table 2, the initial collapse pressure of undisturbed loess is $75 \mathrm{kPa}$, and the saturated density of overlying soil is calculated according to

$$
\rho_{s}=\rho_{d}\left(1+\frac{S_{r} e}{d_{s}}\right),
$$

where $\rho_{s}$ is the saturated density of loess $\left(\mathrm{g} / \mathrm{cm}^{3}\right), \rho_{d}$ is the dry density of soil $\left(\mathrm{g} / \mathrm{cm}^{3}\right), S_{r}$ is the saturation of soil, $S_{r}=85 \%, e$ is the void ratio of loess, and $d_{\mathrm{s}}$ is the relative density of loess particles.

When $\rho_{s}=1.67 \mathrm{~g} / \mathrm{cm}^{3}$ and $p_{1}=200 \mathrm{kPa}, \delta_{s}>0.07$, which indicates that the loess in this test has a great collapse potential according to the "standard for building construction in collapsible loess regions" (GB 50025-2018), and the collapse of the loess sample is strong. The collapse coefficient $\delta_{\mathrm{s}}$ under different $p_{1}$ is shown in Table 3.

3.3. Test Method of Loess Collapse of Unloading. In this paper, the conventional collapsibility test was carried out first, and then, the unloading collapse test was carried out. Under the effect of the initial pressure, the intact loess sample was compressed and stabilized under the natural water content, and then, the loess is soaked in water to let the loess collapse. When the loess completed different collapse amounts, different degrees of vertical unloading were carried out, and the collapse deformation after unloading was measured. (in the unloading collapse test, there is no rebound phenomenon worthy of consideration, and the unloading rebound deformation can be ignored). Second, the intact loess was compressed at a prescribed initial pressure. Then, the loess was subjected to wetting when the compression deformation of loess was stable, and the collapse deformation began to increase. Unloading collapse tests were performed when the loess completed the amount of collapse to some extent, and the unloading collapse deformation of loess was measured. The loess unloading collapse test scheme is shown in Table 4.

\section{Characteristic Analysis of Loess Collapse of Unloading}

4.1. Unloading Collapse Test Results. Consequently, 384 oedometer unloading collapse tests were performed. The outputs of the experimental work are as follows. Figure 1 


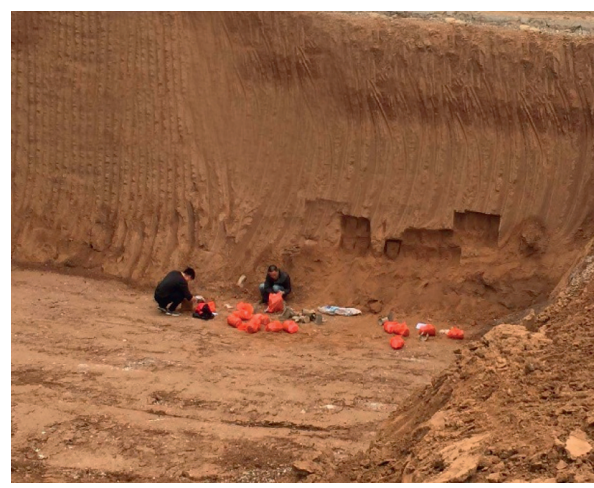

(a)

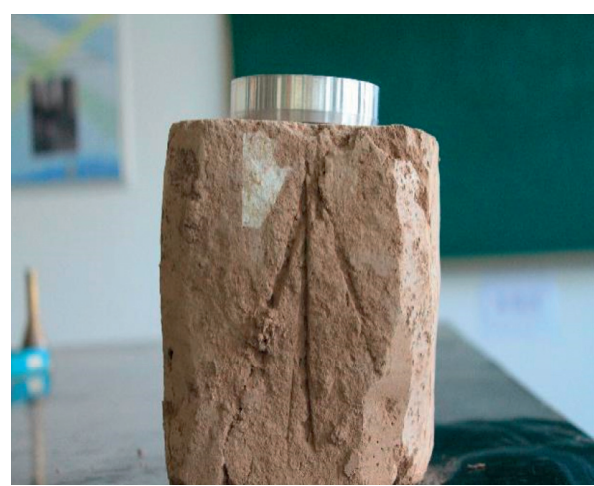

(c)

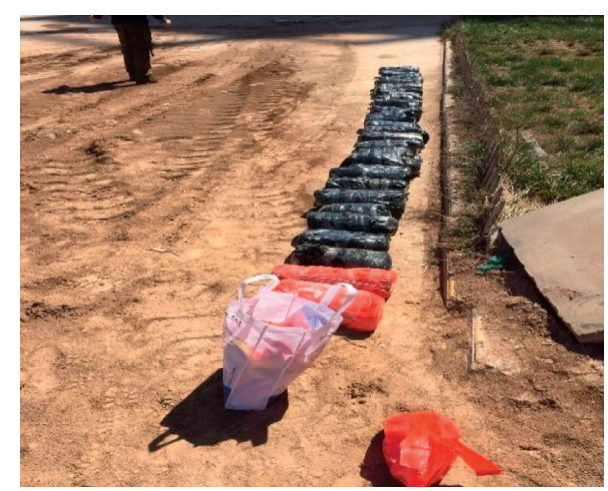

(b)

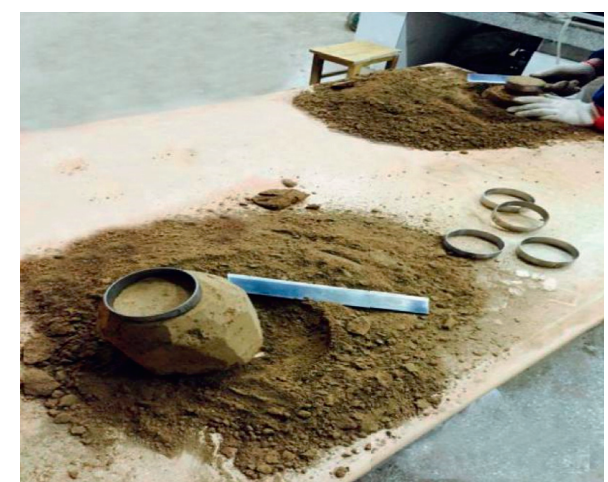

(d)

FiguRE 1: Site sampling and laboratory preparation process.

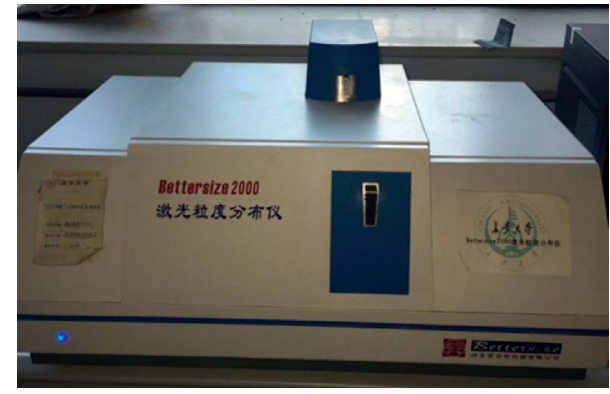

Figure 2: Bettersize 2000 laser particle size analyzer.

shows that the initial pressure, unloading ratio, and collapsecompleted ratio significantly affect the remnant loess collapse. The family of curves of different initial pressures represents the unloading collapse test with different collapse ratios.

The collapse potential after unloading decreases with the decreasing $K$ for the same $\eta$, whereas the slope of the curves decreases. Thus, with an increasing amplitude of vertical unloading, the collapse deformation of loess gradually decreases. The reason is that the self-weight collapsible loess is generally characterized by sudden and substantial deformations that occur when inundation is applied under constant stress. With the decrease in effective normal stress of the framework particles, the effects of displacement, dislocation, and collapse among the loess particles are weakened. Hence, the collapse deformation of loess decreases.

Figure 4 also shows that the collapse potential decreases because of an increase in $\eta$ for the same $K$. First, the likely reason is the open pores of various diameters and shapes, which are formed by the framework particles that connect with one another by point contact connection because the collapse is processed in parts of dissolving salt crystals and ion exchange among the particles. The connection among the particles can be destroyed. Second, after the loess begins to collapse, its structure is dramatically destroyed, which is closely related to the abundance of large pores in the loess. The presence of large pores decreases with the increasing collapse amount. Thus, the loess deformation will be reduced if collapse occurs again after unloading.

4.2. Unloading Effect Coefficient i of Loess Collapse. Based on the results of the unloading collapse test, to investigate the extent of the unloading effect of collapse, the unloading effect coefficient $i$ is defined as follows:

$$
i=\frac{1-\delta_{r}}{\delta_{s}},
$$

where $\delta_{s}$ is the collapse coefficient of loess under constant initial pressure and $\delta_{\mathrm{r}}$ is the remnant collapse coefficient under the effect of unloading.

If the unloading has no effect on the collapse process of loess, the unloading effect coefficient $i$ is 1 . The value of $i$ is 
TABLe 1: Physical properties of intact loess.

\begin{tabular}{|c|c|c|c|c|c|c|c|c|}
\hline \multirow{2}{*}{$\begin{array}{l}\text { Water content } \\
\omega(\%)\end{array}$} & \multirow{2}{*}{$\begin{array}{c}\text { Density } \\
\mathrm{P}\left(\mathrm{g} \cdot \mathrm{cm}^{-3}\right)\end{array}$} & \multirow{2}{*}{$\begin{array}{c}\text { Void ratio } \\
e\end{array}$} & \multirow{2}{*}{$\begin{array}{c}\text { Liquid limit } \\
\omega_{\mathrm{L}}(\%)\end{array}$} & \multirow{2}{*}{$\begin{array}{c}\text { Plastic limit } \\
\omega_{\mathrm{p}}(\%)\end{array}$} & \multirow{2}{*}{$\begin{array}{c}\text { Plastic index } \\
I_{\mathrm{p}}\end{array}$} & \multicolumn{3}{|c|}{ Particles content } \\
\hline & & & & & & $>0.05$ & $0.05-0.005$ & $<0.005$ \\
\hline 13.6 & 1.35 & 1.27 & 27.3 & 17.9 & 9.4 & 19.32 & 63.56 & 17.12 \\
\hline
\end{tabular}

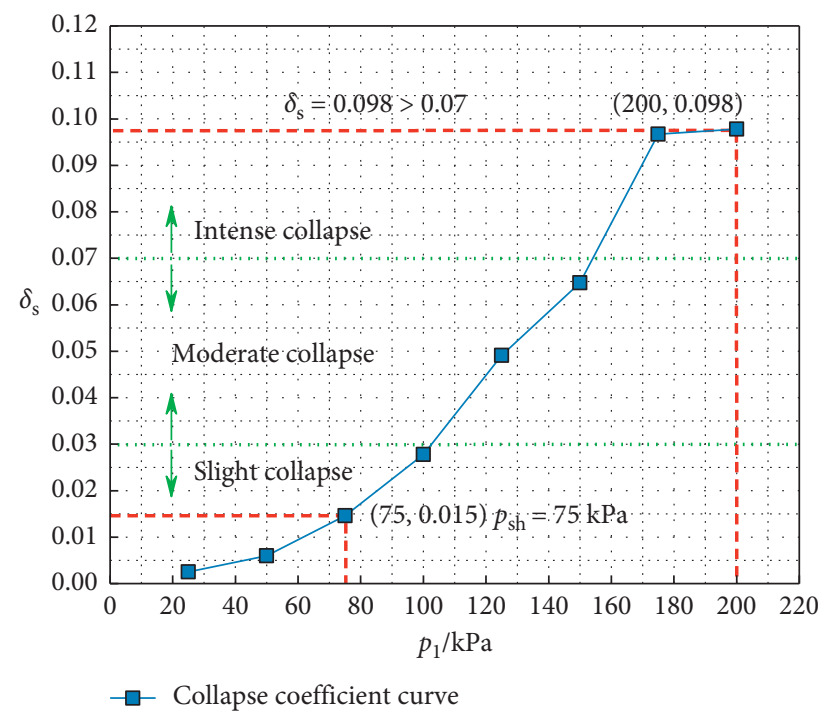

FIGURE 3: Relationship curves of $\delta_{\mathrm{s}}$ and $(p)_{1}\left((p)_{1} \leq 200 \mathrm{kPa}\right)$.

TABle 2: $\delta_{\mathrm{s}}$ of loess under different $p_{1}\left(p_{1} \leq 200 \mathrm{kPa}\right)$.

\begin{tabular}{lcccccccc}
\hline$p_{1}(\mathrm{kPa})$ & 25 & 50 & 75 & 100 & 125 & 150 & 175 & 200 \\
\hline$\delta_{s}$ & 0.0025 & 0.0060 & 0.0146 & 0.0278 & 0.0491 & 0.0647 & 0.0967 & 0.0978 \\
\hline
\end{tabular}

TABLE 3: $\delta_{\mathrm{s}}$ of loess under different $p_{1}$.

\begin{tabular}{lcccrr}
\hline$p_{1}(\mathrm{kPa})$ & 200 & 250 & 300 & 350 & 400 \\
\hline$\delta_{s}$ & 0.098 & 0.118 & 0.142 & 0.161 & 0.163 \\
\hline
\end{tabular}

TABLE 4: Test scheme of unloading collapse tests.

\begin{tabular}{|c|c|c|c|c|c|}
\hline$p_{1}(\mathrm{kPa})$ & $\eta(\%)$ & \multicolumn{4}{|c|}{$\Delta p(\mathrm{kPa})$} \\
\hline 200 & 20 & 25 & 50 & 75 & 100 \\
\hline 250 & 40 & 25 & 50 & 75 & 100 \\
\hline 300 & 60 & 50 & 100 & 150 & 200 \\
\hline 350 & & 50 & 100 & 150 & 200 \\
\hline 400 & 80 & 50 & 100 & 150 & 200 \\
\hline
\end{tabular}

less than 1, which indicates that unloading has an effect on the collapse process of loess, and the greater the deviation from 1, the greater the influence of unloading on the collapse deformation of loess. According to $\delta_{\mathrm{s}}$ measured by the conventional collapse test of loess and the remnant collapse coefficient $\delta_{\mathrm{r}}$ of different collapse degrees $\eta$ under the unloading effect, the unloading effect coefficient $i$ is obtained, as shown in Figure 5.

It can be seen from Figure 5 that the unloading effect coefficients under various initial pressures are less than 1 , which indicates that unloading makes the collapse of loess smaller, and the influence coefficient is even less than 0.5 , and the effect of unloading on collapsible deformation of loess is obvious.

Under the same collapse completion ratio $\eta$, the effect of unloading on collapsible deformation of loess increases with the decrease of the unloading ratio $K$, that is, the greater the unloading amount, the greater the effect. Under the same unloading ratio $K$, with the increase of the collapse completion ratio $\eta$, the effect of unloading on collapse 

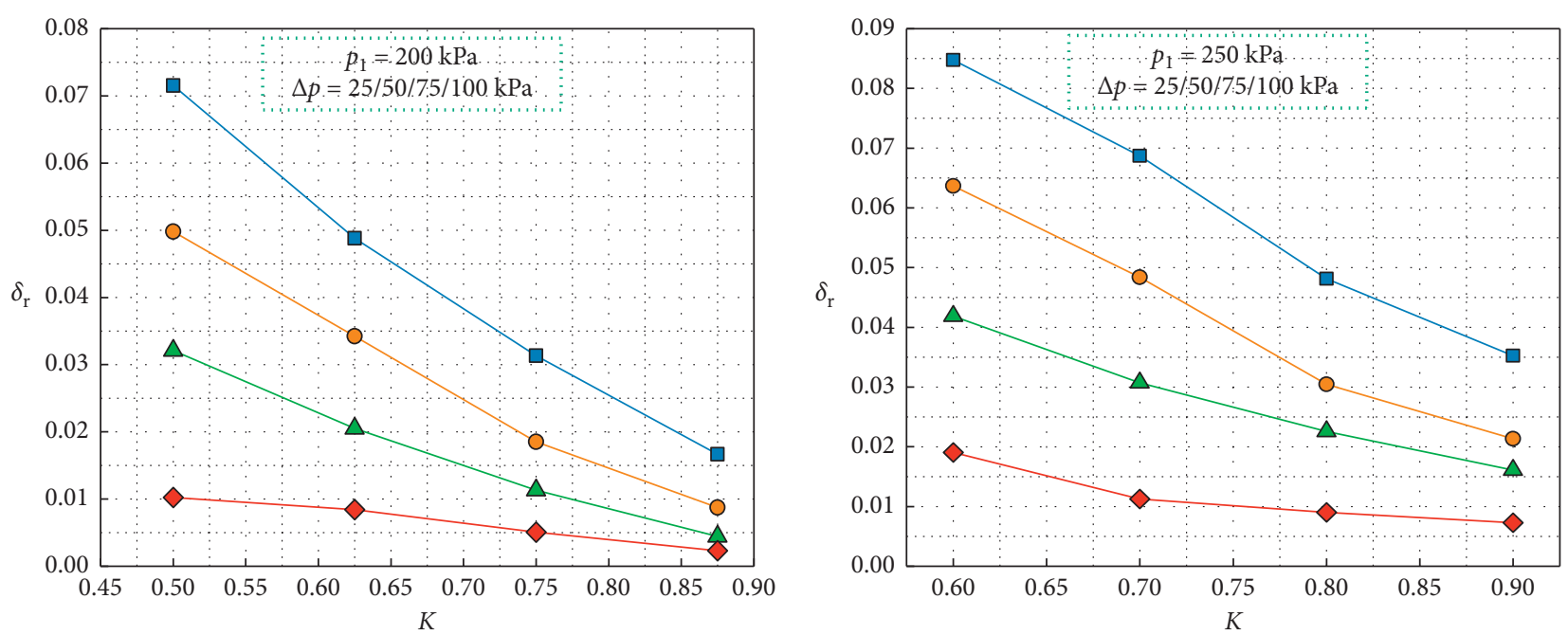

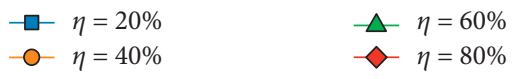

(a)

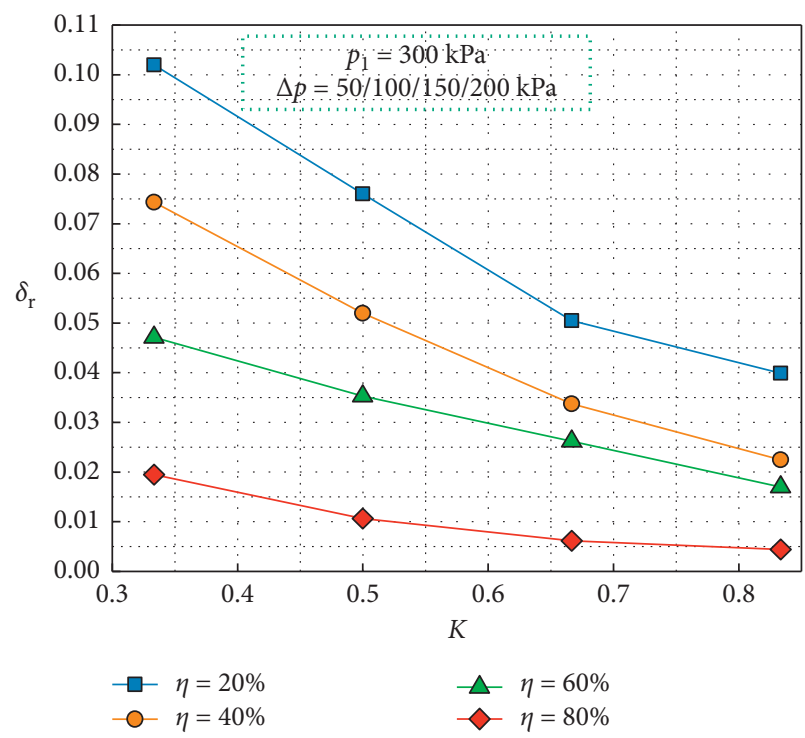

(c)

$$
\begin{array}{ll}
\neg \eta=20 \% & \triangle \eta=60 \% \\
\bigcirc \eta=40 \% & \checkmark \eta=80 \%
\end{array}
$$

(b)

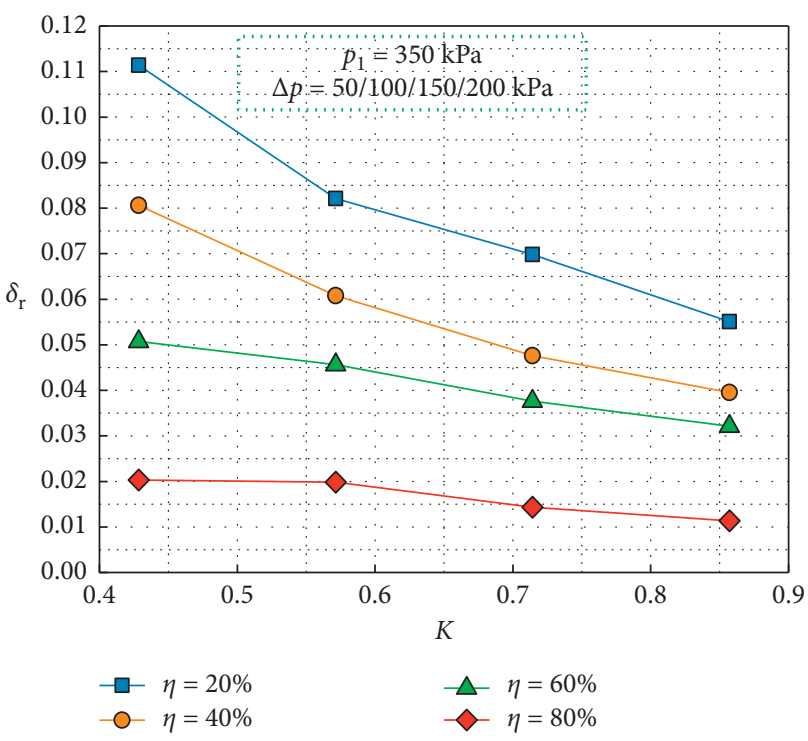

(d)

Figure 4: Continued. 


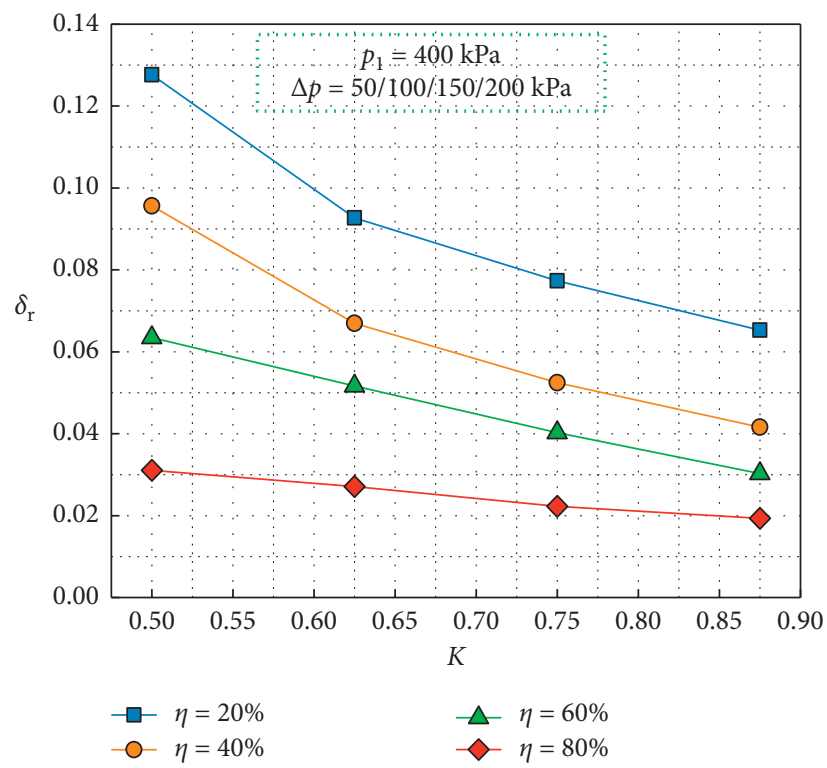

(e)

Figure 4: Relationship curves of $\delta \mathrm{r}$ and $K$. (a) $p 1=200 \mathrm{kPa}$. (b) $p 1=250 \mathrm{kPa}$. (c) $p 1=300 \mathrm{kPa}$. (d) $p 1=350 \mathrm{kPa}$. (e) $p 1=400 \mathrm{kPa}$.

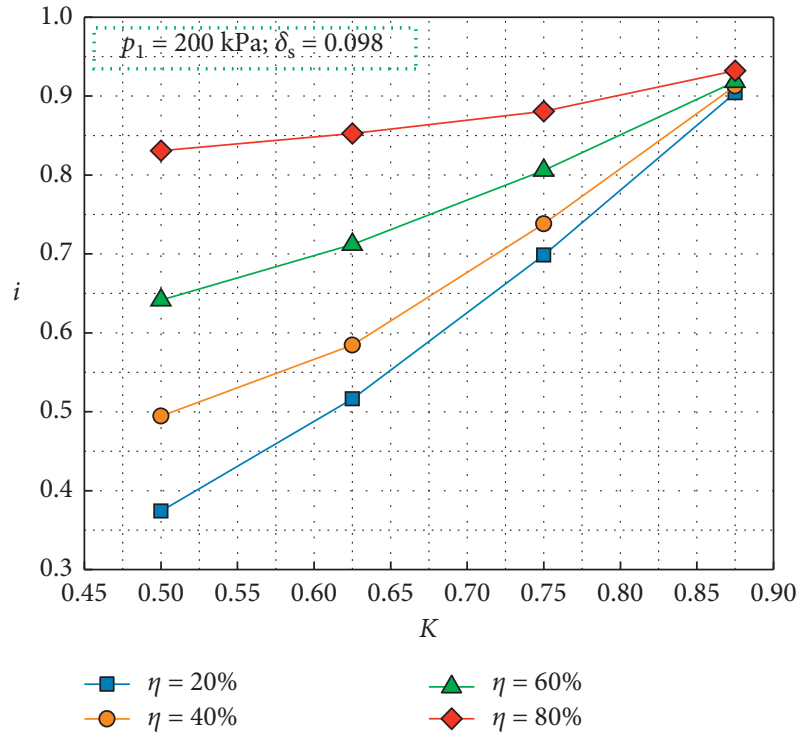

(a)

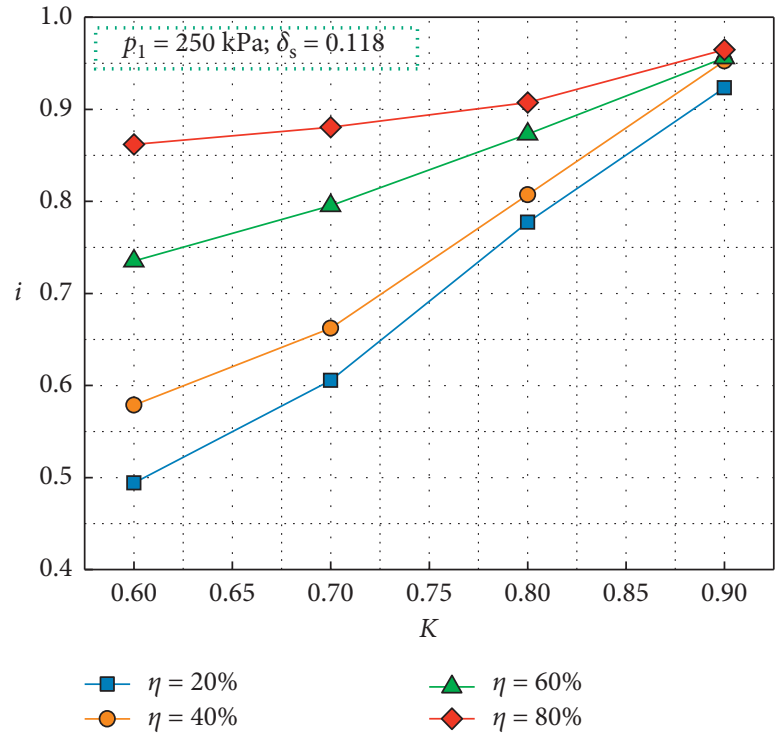

(b)

Figure 5: Continued. 


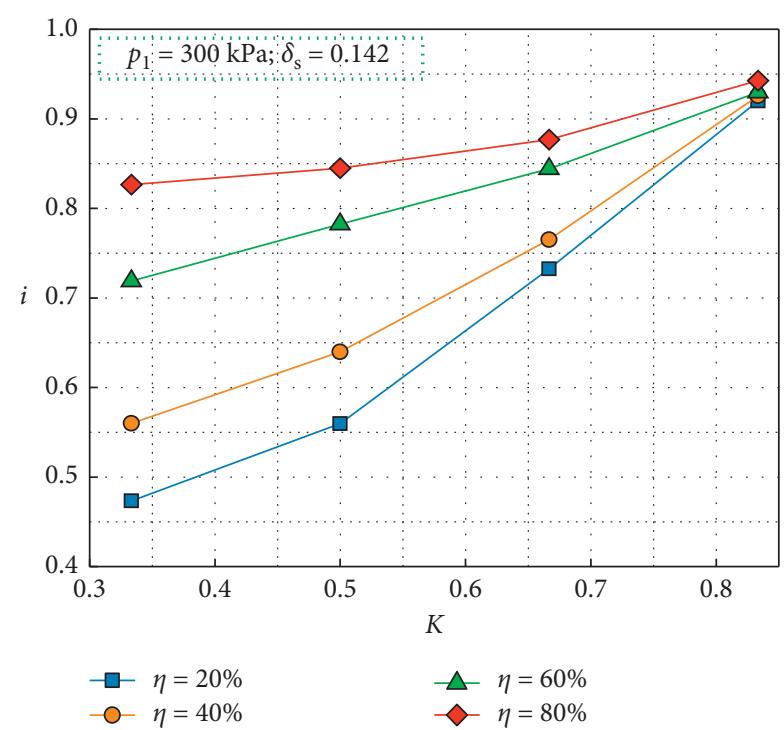

(c)

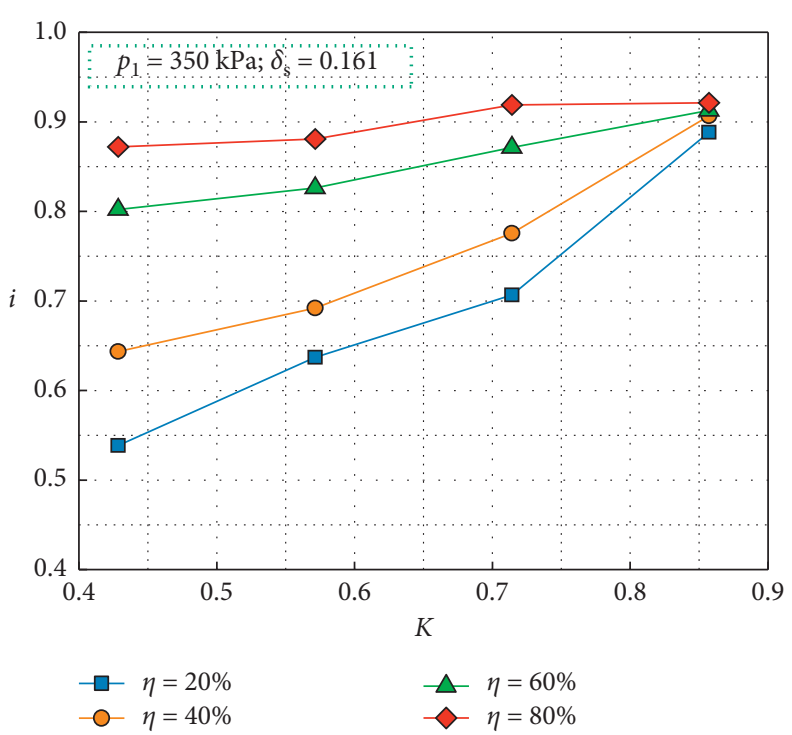

(d)

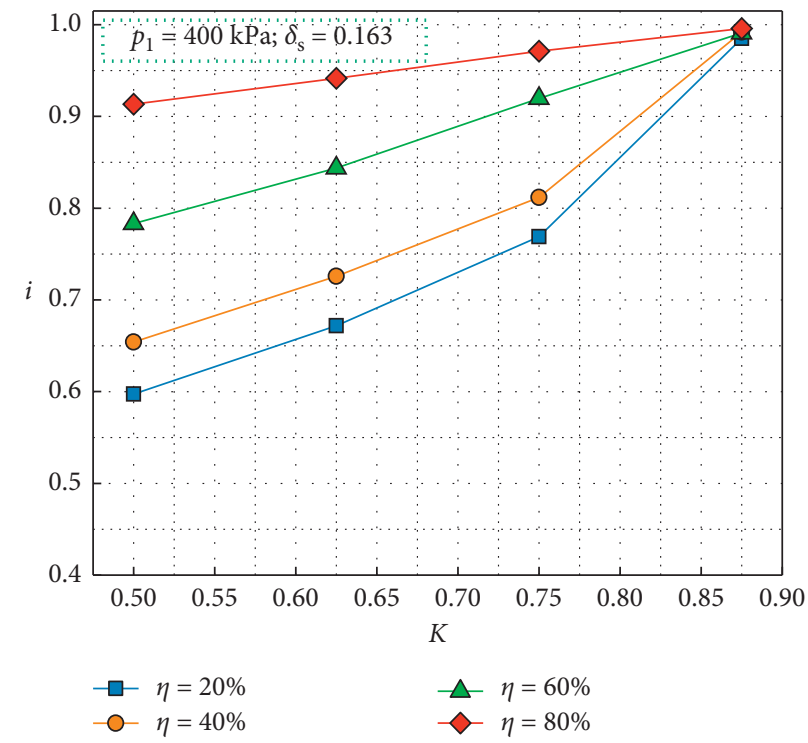

(e)

Figure 5: Relationship curves of $i$ and $K$. (a) $p 1=200 \mathrm{kPa}$. (b) $p 1=250 \mathrm{kPa}$. (c) $p 1=300 \mathrm{kPa}$. (d) $p 1=350 \mathrm{kPa}$. (e) $p 1=400 \mathrm{kPa}$.

deformation gradually weakens, namely, the greater the collapse completion under the initial pressure, the smaller the impact of unloading; on the contrary, the smaller the collapse completion under the initial pressure, the greater the impact of unloading.

When $p_{1}$ is $400 \mathrm{kPa}$, unloading $50 \mathrm{kPa}$ almost has no impact on the collapse process, and $i$ is slightly less than 1 . Table 3 also shows that when the initial pressure is greater than $350 \mathrm{kPa}$, the loess collapse deformation has almost no increase with increasing initial pressure. When the vertical pressure is released from $400 \mathrm{kPa}$ to $350 \mathrm{kPa}$, the unloading has almost no effect on the collapse process. Thus, there is a threshold value of $p_{1}$ ( $350 \mathrm{kPa}$ for the test loess sample). When $p_{1}$ is greater than the threshold value, neither loading nor unloading affects the collapse deformation of loess.
When $p_{1}$ is less than the threshold value, unloading significantly affects the collapse deformation of loess. Therefore, the collapse amount after unloading must be determined when analyzing or solving practical project problems. The results of Figure 4 are used to find a method to determine the coefficient of remnant collapse.

To investigate the curve features in Figure 4, the nonlinear allometric model is performed using the relationships between the remnant collapse coefficient and the unloading ratio. The relationship is defined as follows:

$$
\delta_{r}=a K^{b},
$$

where the parameters of Equation (7) are obtained based on the regression analysis of unloading collapse tests with 


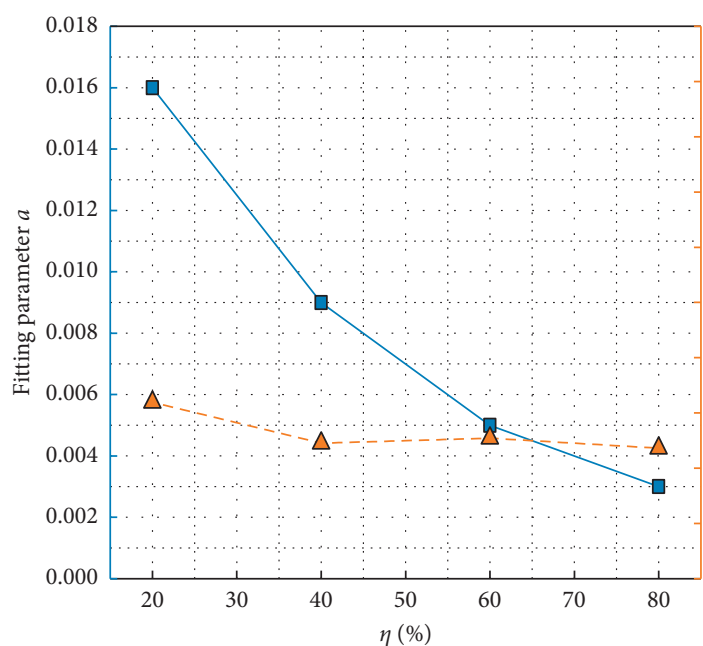

(a)

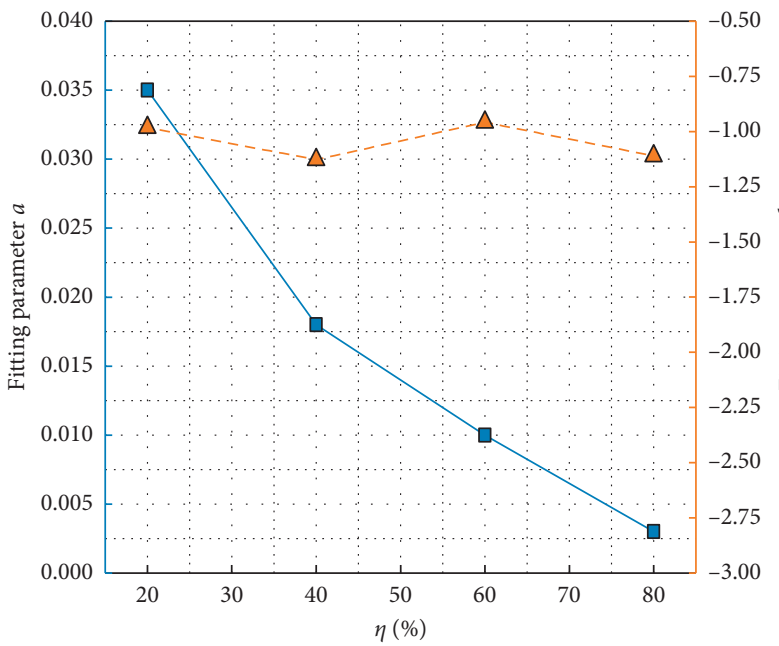

(c)
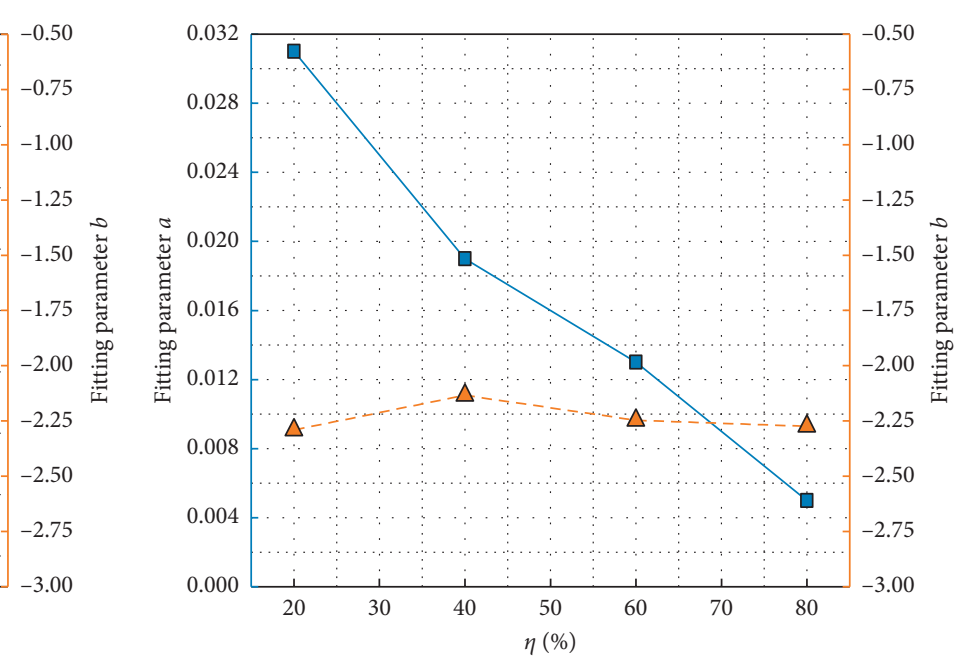

(b)

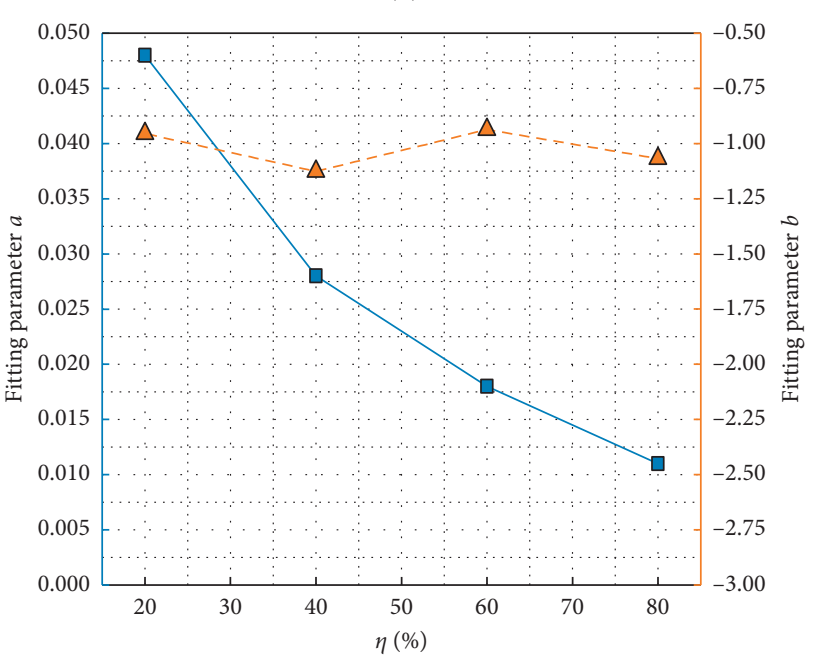

(d)

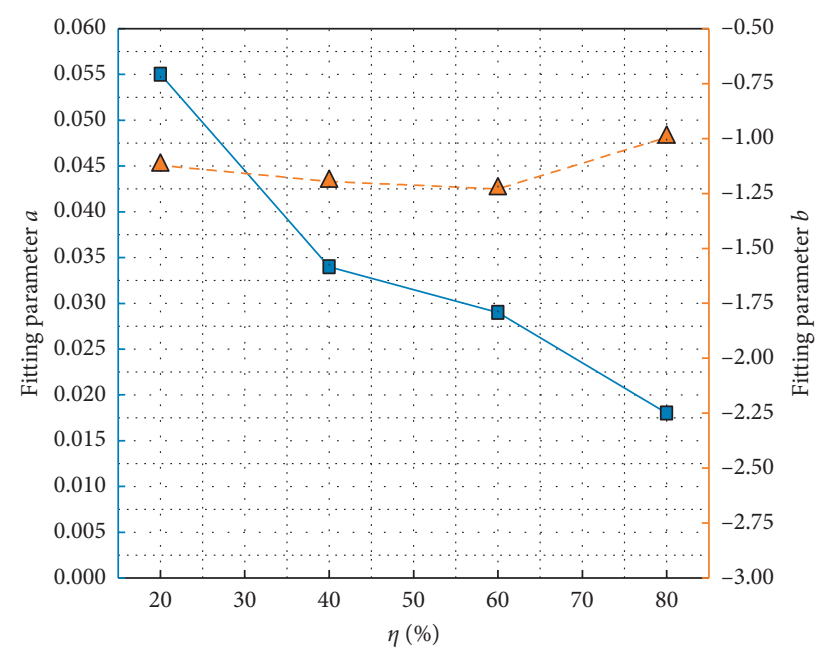

(e)

Figure 6: The trend of regression parameters a and b with $\eta$ under different p1. (a) $p 1=200 \mathrm{kPa}$. (b) $p 1=250 \mathrm{kPa}$. (c) $p 1=300 \mathrm{kPa}$. (d) $p 1=350 \mathrm{kPa}$. (e) $p 1=400 \mathrm{kPa}$. 
TABLE 5: The coefficient of determination $\left(R^{2}\right)$ of equation (7).

\begin{tabular}{lcccc}
\hline \multirow{2}{*}{$p_{1}(\mathrm{kPa})$} & \multicolumn{4}{c}{$\eta_{1}(\%)$} \\
& 20 & 40 & 60 & 80 \\
\hline 200 & 0.962 & 0.958 & 0.965 & 0.887 \\
250 & 0.972 & 0.976 & 0.995 & 0.972 \\
300 & 0.977 & 0.976 & 0.961 & 0.998 \\
350 & 0.994 & 0.999 & 0.958 & 0.826 \\
400 & 0.992 & 0.998 & 0.978 & 0.983 \\
\hline
\end{tabular}

TABLE 6: The relationship between $a, \eta$, and ${ }^{-} b$ under different $p_{1}$.

\begin{tabular}{lcc}
\hline$p_{1}(\mathrm{kPa})$ & Relationship between $a$ and $\eta$ & $\bar{b}$ \\
\hline 200 & $a=0.50 \eta^{-1.03}$ & -2.44 \\
250 & $a=0.51 \eta^{-1.06}$ & -2.41 \\
300 & $a=0.56 \eta^{-0.98}$ & -1.16 \\
350 & $a=0.52 \eta^{-0.92}$ & -1.12 \\
400 & $a=0.57 \eta^{-0.95}$ & -1.12 \\
\hline
\end{tabular}

different initial pressures. Figure 6 describes the changes of regression parameters $a$ and $b$ with $\eta$ under different $p_{1}$.

In order to further verify the prediction ability of Equation (7) for residual collapse deformation, under different parameters, the coefficient of determination $\left(R^{2}\right)$ under different $p_{1}$ and $\eta$ are shown in Table 5 .

As can be seen from Figure 6 and Table 5, the parameter $a$ changes with the change of $\eta$, while the parameter $b$ changes little with $\eta$ under different initial pressures. Therefore, under different $p_{1}$, take the mean value of $b$ and list the relationship between $a$ and $\eta$, as shown in Table 6 .

Furthermore, the expression of the parameter $a$ under different initial pressure conditions in Table 6 is simplified, and the expression of $a$ is shown in

$$
\begin{aligned}
& a=\frac{0.53}{\eta}, \\
& b=-2.43, \quad\left(p_{1} \leq 250 \mathrm{kPa}\right), \\
& b=-1.13, \quad\left(250 p<p_{1} \leq 400 \mathrm{kPa}\right) .
\end{aligned}
$$

The loess collapse effect coefficient $i$ of unloading is obtained by substituting Equation (8) into Equation (6). The relation is shown as follows:

$$
i=1-\frac{0.53}{\eta \delta_{s}} K^{b}
$$

In summary, $i$ needs to obtain only the collapse $\delta_{s}$, collapse completion ratio $\eta$, and unloading ratio $K$. Therefore, if $i$ is adopted, rapid analysis of the unloading loess collapse will be realized. Thus, considering the unloading effect, the unloading loess collapse coefficient can be defined as $i \delta_{s}$, which can be used to calculate the collapse amount of unloading and provide the basis for loess collapse problems caused by unloading.

\section{Conclusion}

(1) In terms of loess collapse after unloading, the remnant collapse coefficient decreases with the decreasing unloading ratio at constant collapsecompleted ratios. The remnant collapse coefficient decreases with the increasing collapse-completed ratio at constant unloading ratios.

(2) There is a threshold value of the initial pressure (the threshold value of the specimen in this paper is $350 \mathrm{kPa}$ ). When $p_{1}$ is greater than the threshold value, neither loading nor unloading affects the loess collapse deformation. When $p_{1}$ is less than the threshold value, the unloading affects the loess collapse deformation. The extent of the loess collapse effect of unloading increases with decreasing $K$ for the same $\eta$. The effect of unloading decreases with increasing $\eta$ for the same $K$.

(3) The expression of $\delta_{\mathrm{r}}$ and $i$ can be used to calculate the collapse amount after unloading and provide a practical evaluation method for loess collapse deformation on the effect of unloading.

\section{Data Availability}

The data used to support the findings of this study are available from the corresponding author upon request.

\section{Conflicts of Interest}

The authors declare that there are no conflicts of interest regarding the publication of this paper.

\section{Acknowledgments}

The work was financially supported by the Xi'an Technological University Initial Scientific Research Fund of Young Teacher and Key Research and Development Program of Shaanxi (Program no. 2018ZDCXL-SF-30-9).

\section{References}

[1] Y. Li, W. Shi, A. Aydin, M. A. Beroya-Eitner, and G. Gao, "Loess genesis and worldwide distribution," Earth-Science Reviews, vol. 201, Article ID 102947, 2020.

[2] L. Wang, S. Shao, and F. She, "A new method for evaluating loess collapsibility and its application," Engineering Geology, vol. 264, Article ID 105376, 2020.

[3] J. Xu, J. Ren, Z. Wang, S. Wang, and J. Yuan, "Strength behaviors and meso-structural characters of loess after freezethaw," Cold Regions Science and Technology, vol. 148, pp. 104-120, 2018.

[4] I. M. Litvinov, "Changes in the properties of settled loessial soils with depth after compaction of the soils by wetting and the effects of blasting," Soil Mechanics and Foundation Engineering, vol. 4, no. 6, pp. 419-421, 1967.

[5] E. S. Chalikova and E. V. Stepanova, "Methods of accelerated determination of the life of silicate-stabilized loess," Soil Mechanics and Foundation Engineering, vol. 11, no. 3, pp. 200-203, 1974.

[6] A. J. Lutenegger, "Engineering properties and zoning of loess and loess-like soils in China: discussion," Canadian Geotechnical Journal, vol. 20, no. 1, pp. 192-193, 1983.

[7] J. Feda, "Collapse of loess upon wetting," Engineering Geology, vol. 25, no. 2-4, pp. 263-269, 1988. 
[8] E. Derbyshire, X. Meng, and R. A. Kemp, "Provenance, transport and characteristics of modern aeolian dust in western Gansu province, China, and interpretation of the Quaternary loess record," Journal of Arid Environments, vol. 39, no. 3, pp. 497-516, 1998.

[9] F. M. Francisca, "Evaluating the constrained modulus and collapsibility of loess from standard penetration test," International Journal of Geomechanics, vol. 7, no. 4, pp. 307-310, 2007.

[10] M. Momeni, A. Shafiee, M. Heidari, M. K. Jafari, and M. R. Mahdavifar, "Evaluation of soil collapse potential in regional scale," Natural Hazards, vol. 64, no. 1, pp. 459-479, 2012.

[11] Z. Liu, F. Liu, F. Ma et al., "Collapsibility, composition, and microstructure of loess in China," Canadian Geotechnical Journal, vol. 53, no. 4, pp. 673-686, 2016.

[12] X.-A. Li, L. Wang, Y.-L. Yan, B. Hong, and L.-C. Li, "Experimental study on the disintegration of loess in the Loess plateau of China," Bulletin of Engineering Geology and the Environment, vol. 78, no. 7, pp. 4907-4918, 2019.

[13] Y. Zhao, J. Zhuang, Y. Wang, Y. Jia, P. Niu, and K. Jia, "Improvement of loess characteristics using sodium alginate," Bulletin of Engineering Geology and the Environment, vol. 79, no. 4, pp. 1879-1891, 2020.

[14] J. Xu, Y. Li, W. Lan, and S. Wang, "Shear strength and damage mechanism of saline intact loess after freeze-thaw cycling," Cold Regions Science and Technology, vol. 164, Article ID 102779, 2019.

[15] C. D. F. Rogers, D. I. Boardman, and A. Zourmpakis, "Case study of a loess collapse field trial in Kent, SE England," Quarterly Journal of Engineering Geology \& Hydrogeology, vol. 39, no. 2, pp. 131-150, 2006.

[16] M. Jiang, H. Hu, and F. Liu, "Summary of collapsible behaviour of artificially structured loess in oedometer and triaxial wetting tests," Canadian Geotechnical Journal, vol. 49, no. 10, pp. 1147-1157, 2012.

[17] M. J. Jiang, T. Li, H. J. Hu, and C. Thornton, "DEM analyses of one-dimensional compression and collapse behaviour of unsaturated structural loess," Computers and Geotechnics, vol. 60, pp. 47-60, 2014.

[18] X. Wang, Y. Zhu, and X. Huang, "Field tests on deformation property of self-weight collapsible loess with large thickness," International Journal of Geomechanics, vol. 14, no. 3, Article ID 04014001, 2014.

[19] L. Deng, W. Fan, Y. B. Cao, and Y. P. Yin, "Case study of a collapse investigation of loess sites covered by very thick loesspaleosol interbedded strata," International Journal of Geomechanics, vol. 18, no. 11, Article ID 05018009, 2018.

[20] J. Li, S. Shao, and S. Shao, "Collapsible characteristics of loess tunnel site and their effects on tunnel structure," Tunnelling and Underground Space Technology, vol. 83, pp. 509-519, 2019.

[21] C. Liang, C. Cao, and S. Wu, "Hydraulic-mechanical properties of loess and its behavior when subjected to infiltrationinduced wetting," Bulletin of Engineering Geology and the Environment, vol. 77, no. 1, pp. 385-397, 2018.

[22] S. Shao, Y. Li, and F. Zhou, "Structural damage evolvement properties of collapsible loess," Chinese Journal of Rock Mechanics and Engineering, vol. 23, no. 24, pp. 4161-4165, 2004.

[23] S. Shao, F. Zhou, and C. Song, "Analysis of moistening and compression deformation of loess considering soil structure variations," China Civil Engineering Journal, vol. 6, no. 39, pp. 94-99, 2006.
[24] S. Shao, A.-Z. Luo, and Q.-G. Yu, "Structural damage properties of $\mathrm{Q}_{3}$ loess under tri-axial loading and moistening," Chinese Journal of Geotechnical Engineering, vol. 28, no. 12, pp. 2077-2081, 2006.

[25] B. Liu, D. Xie, and Z. Guo, "A practical method for moistening deformation of loess foundation," Rock and Soil Mechanics, vol. 25, no. 2, pp. 270-274, 2004.

[26] M. Zhang, Y. Xie, and B. Liu, "Study on constitutive relation of loess moistening deformation based on secant-modulus method," Chinese Journal of Rock Mechanics and Engineering, vol. 25, no. 3, pp. 609-617, 2006.

[27] L. Xu, F. C. Dai, L. G. Tham et al., "Field testing of irrigation effects on the stability of a cliff edge in loess, north-west China," Engineering Geology, vol. 120, no. 1-4, pp. 10-17, 2011.

[28] C. W. W. Ng, H. Sadeghi, S. K. B. Hossen, C. F. Chiu, E. E. Alonso, and S. Baghbanrezvan, "Water retention and volumetric characteristics of intact and re-compacted loess," Canadian Geotechnical Journal, vol. 53, no. 8, pp. 1258-1269, 2016.

[29] P. An, A. Zhang, Y. Xing, B. Zhang, W. Ni, and W. Ren, "Experimental study on settling characteristics of thick selfweight collapsible loess in Xinjiang Ili region in China using field immersion test," Soils and Foundations, vol. 58, no. 6, pp. 1476-1491, 2018.

[30] X. Weng, Y. Sun, Y. Zhang, H. Niu, X. Liu, and Y. Dong, "Physical modeling of wetting-induced collapse of shield tunneling in loess strata," Tunnelling and Underground Space Technology, vol. 90, pp. 208-219, 2019.

[31] X. Hou, S. K. Vanapalli, and T. Li, "Wetting-induced collapse behavior associated with infiltration: a case study," Engineering Geology, vol. 258, Article ID 105146, 2019.

[32] I. Mashhour and A. Hanna, "Drag load on end-bearing piles in collapsible soil due to inundation," Canadian Geotechnical Journal, vol. 53, no. 12, pp. 2030-2038, 2016.

[33] H. Xing and L. Liu, "Field tests on influencing factors of negative skin friction for pile foundations in collapsible loess regions," International Journal of Civil Engineering, vol. 16, no. 10, pp. 1413-1422, 2018.

[34] E. Rodriguez Rincón, R. P. d. Cunha, and B. Caicedo Hormaza, "Analysis of settlements in piled raft systems founded in soft soil under consolidation process," Canadian Geotechnical Journal, vol. 57, no. 4, pp. 537-548, 2020.

[35] China Planning Press, Ministry of Construction of the People's Republic of China, GB/T 50123-1999 Standard for Soil Test Method, China Planning Press, Beijing, China, 1999.

[36] Ministry of Housing and Urban-Rural Development of the People's Republic of China, GB 50028-2018 Standard for Building Construction in Collapsible Loess Regions, China Architecture and Building Press, Beijing, China, 2018. 